\title{
LA CONSTRUCCIÓN DISCURSIVA DEL ESPACIO Y TIEMPO EN CÓMO ME HICE MONJA, DE CÉSAR AIRA
}

The discursive construction of space and time in César Aria's Cómo me hice monja

Ilse Alejandra Gámez Reza, Tecnológico de Monterrey, México Correo electrónico: alejandra_gamez@hotmail.com

Recepción: 10/07/2019

Aceptación: 11/02/2020

Resumen. El presente artículo aborda la novela Cómo me hice monja del autor argentino César Aira, desde un análisis de la construcción discursiva de las categorías espacio y tiempo, pues resultan fundamentales para la particular narrativa de este autor, especialmente en ésta, una de sus muchas novelas cortas. Para lograr el análisis se abordan los implícitos discursivos que desde distintas corrientes teóricas forman parte de la construcción discursiva permitiendo determinar el uso del lenguaje y la narrativa de Aira, además el estudio se centra en diferenciar los explícitos y reconocer el papel que cada uno desempeña. Se examinan las categorías de espacio y tiempo pues ambas se relacionan constantemente en la obra de César Aira para dar lugar a autoficciones y relatos vanguardistas.

Palabras clave: espacio, tiempo, discurso, implícito, sobreentendido.

Abstract. This article analyzes the discursive construction of the categories space and time; those categories are fundamental for the peculiar narrative of Argentinian author Cesar Aria's novel Cómo me hice monja, especially in this one, one of his many short novels. To achieve the analysis the implications are addressed since different theorical perspectives that are part of the discursive construction allowing understand the use of language and the narrative of Aira, also the study centers in the difference between the explicit discursive and the discursive implicit and their roles. The article examines the categories of space and time, because both are closely related in the Aira's novels to make place to self-fiction and vanguard narrative.

Keywords: space, time, discourse, implicit, implied. 


\section{enn-claves}

\section{Introducción}

Las categorías de espacio y tiempo son recurrentes en la literatura, ambas aparecen continuamente de manera explícita o implícita en narraciones, marcando una pauta para el contenido y el desarrollo del discurso. En el particular caso de César Aira, y su amplia producción de novelas cortas, ambas categorías son de suma importancia, y si bien no han sido analizadas con tanta profundidad como el proceso creativo del autor o la autoficción desarrollada por el mismo, sí juegan un papel fundamental en algunos de sus títulos. Justamente para demostrarlo este estudio se dedica al análisis de los conceptos de espacio y tiempo ya no en su generalidad sino en una obra específica, Cómo me hice monja, que resulta el corpus de la presente investigación. La investigación parte de corrientes teóricas como la narratología, que ofrece un marco conceptual para el análisis; el análisis del discurso, desde los implícitos y explícitos permitiendo retomar fragmentos del corpus para definir la innovación del uso de las categorías de espacio y tiempo en la obra seleccionada y estimar la innovación de Aira en el relato.

\section{Devenir, aceleración y memoria. Temporalidad en Cómo me hice monja}

La novela corta Cómo me hice monja presenta una historia con fuerte tendencia autobiográfica, narrada en primera persona por el niño Aira, quien dependiendo del fragmento de la obra puede identificarse como niño o niña y quien vincula la realidad con la ficción. Esta narración ha sido reconocida y estudiada sobre todo por su naturaleza autoficticia, pues si bien se identifican elementos relacionados con la biografía del autor no todo resulta realista, ya que la novela se encuentra plagada de elementos ficticios. Para que esto sea posible el tiempo desempeña un papel fundamental en el relato. En Cómo me hice monja se narran eventos de la infancia del protagonista desde una memoria perfecta y con la aparición de una serie de pesadillas que pueden identificarse como una matriz del texto principal. ${ }^{1}$

Para contar con un marco de referencia que permita realizar el análisis discursivo de la categoría de tiempo en la novela, vale la pena retomar algunas nociones fundamentales de narratología, que ofrecen elementos para enriquecer la investigación.

\footnotetext{
${ }^{1}$ Margarita Remón, "La narrativa de César Aira: una sorpresa continua e ininterrumpida", Foro Hispánico: Revista Hispánica de Flandes y Holanda, núm. 24 (2003): 55. 


\section{enn-claves}

Revista de Filosofía, Arte, Literatura, Historia

De acuerdo con Rimmon-Kenan, la categoría de historia designa los hechos narrados, abstraídos en su disposición en el texto y reconstruidos en su orden cronológico, junto con los participantes de los hechos, mientras que narración es el acto o proceso de la producción narrativa. ${ }^{2}$ Por su parte, Bal reconoce la historia como una serie de acontecimientos lógica y cronológicamente relacionados que unos actores causan o experimentan, dichos acontecimientos se combinan en un tiempo y lugar indicados con mayor o menor precisión, en tanto el relato es una historia presentada de cierta manera, con una ordenación determinada. ${ }^{3}$ Para Gerald Prince, el relato se define como la representación de por lo menos dos acontecimientos o situaciones reales o ficcionales en una secuencia temporal. Si bien los autores mencionados llegan a diferir al tratar las categorías de historia, narración o relato, sus coincidencias permiten reconocer que la transformación operada en el tiempo es requisito indispensable para la narratividad. Para que exista un relato deben darse transformaciones temporales, que encadenadas unas con otras de manera sucesiva puedan construir una secuencia, de ahí que el tiempo resulte una categoría fundamental en el relato en general y en la novela de Aira en particular. Es cierto que el principio mismo de la sucesión constituye la forma de temporalidad más elemental, es decir, un acontecimiento tras otro, sin embargo, no todas las historias son narradas con una secuencia de esta naturaleza, además, no basta sólo la secuencia para tener una historia que contar, si bien debe existir una secuencia de orden cronológico, también debe darse una de orden lógico. Aira representa justamente a un autor que juega con la temporalidad en sus obras, logrando el orden lógico en los relatos sin seguir el orden cronológico acostumbrado.

Para el filósofo francés Paul Ricouer, un acontecimiento inscrito en la temporalidad humana - es decir, un acontecimiento que tenga sentido - no se restringe a una ocurrencia singular, aislada de otras, sino que se define como el hacer propio de un agente en relación con otros. ${ }^{4}$ Esta idea de historia como una serie de acontecimientos interrelacionados implica la existencia de una doble organización temporal. Por una parte, los acontecimientos ordenados de acuerdo a la cronología y, por otra, la orientación de los acontecimientos en función de una selección que busca determinada finalidad. Así,

\footnotetext{
${ }^{2}$ Shlomith Rimmon-Kennan, Narrative fiction: Contemporary poetics (Nueva York: Routledge, 2002), 6.

${ }^{3}$ Mieke Bal, Teoría de la narrativa. Una introducción a la narratología (Madrid: Cátedra, 1990), 16.

${ }^{4}$ Paul Ricoeur, Tiempo y narración I, trad. Agustín Neira (México: Siglo XXI, 2007), 34.

En-claves del pensamiento, Año XIV, Núm 27, enero-junio 2020, 39-58
} 


\section{enn-claves}

los acontecimientos entramados se orientan a una totalidad significante, motivo por el cual la historia nunca es inocente.

En el particular caso de Cómo me hice monja, la disposición de los acontecimientos y el manejo de la temporalidad del relato, la hacen una novela considerada vanguardista, en donde la finalidad se alcanza gracias a saltos temporales constantes. Teniendo en cuenta que la transformación es una de las condiciones temporales para la novela, es posible identificar en Cómo me hice monja la memoria como punto de anclaje; a través del análisis del discurso se logra el reconocimiento de los implícitos discursivos que presentan esta temporalidad en constante transformación.

Mi historia, la historia de "cómo me hice monja", comenzó muy temprano en mi vida; yo acababa de cumplir seis años. El comienzo está marcado con un recuerdo vívido, que puedo reconstruir en su menor detalle. Antes de eso no hay nada: después todo siguió haciendo un solo recuerdo vívido continuo e ininterrumpido, incluidos los lapsos de sueño, hasta que tomé los hábitos. ${ }^{5}$

A partir de este fragmento inicial del corpus y haciendo uso del análisis del discurso es posible la identificación de implícitos discursivos relacionados con la categoría de tiempo. Por principio de cuentas el narrador reconoce su propia capacidad para tener a la mano todos los recuerdos que le permiten reconstruir la historia detalladamente, lo cual de manera implícita refiere a la capacidad para situar temporalmente los eventos narrados.

Julieta Haidar afirma que el sentido del texto se produce en el juego de lo explícito con lo implícito, ${ }^{6}$ de ahí que para acceder al sentido sea necesario identificar ambos o por lo menos distinguir su participación. La importancia del implícito radica en brindar sentido a través de la inferencia, en este fragmento si bien no aparece en forma obvia o explicita la noción de tiempo ésta se presenta en un sobreentendido, que de acuerdo a Ducrot no designa un acto de habla determinado, sino más bien un proceso de decodificación. En este caso en particular, la decodificación hace ver que la referencia a la edad temprana en que comienza la historia y el recuerdo vívido que se puede

\footnotetext{
${ }^{5}$ César Aira, Cómo me hice monja (Ciudad de México: ERA, 2017), 7.

${ }^{6}$ Julieta Haidar, Debate CEU-Rectoría. Torbellino pasional de los argumentos (México: Universidad Autónoma de México, 2006), 108. 


\section{en-claves}

Revista de Filosofía, Arte, Literatura, Historia

reconstruir en su menor detalle se vinculan con el tiempo definitivamente; es decir, aunque no aparezca el concepto como tal se hace notar que el tiempo es determinante para una historia que recurrirá constantemente a recuerdos y en la que incluso dejan de ser parte del pasado, pues se manifiestan como un presente en transformación. Para el desciframiento de este implícito es necesario el cálculo interpretativo, que vale la pena reconocer nunca es completamente confiable. ${ }^{7}$ A pesar de la desconfianza a la que se pueda prestar dicho cálculo interpretativo, que permite aclarar el sobreentendido y, por tanto, el implícito discursivo, éste deja de manifiesto a través del hacer que alguien piense algo la importancia de la temporalidad en la narrativa de la obra. Sin duda, para todo relato el tiempo es una categoría definitiva, los relatos de César Aira no son la excepción, aunque el autor lleva la importancia de la temporalidad más lejos al romper la continuidad narrativa sin dejar de lado el orden lógico.

El recurrir a recuerdos para contar la historia es reiterado a lo largo de la obra, cuyo encadenamiento lógico-cronológico se da en función de una serie de memorias vívidas del narrador protagonista. Para Luz Aurora Pimentel, en el discurso narrativo hay una correlación de tiempos verbales en términos de anterioridad, posterioridad y/o simultaneidad, articulados y coordinados por medio de adverbios y frases adverbiales del orden de lo temporal que expresan relaciones, entramándolas. ${ }^{8}$ En este primer fragmento que se retoma de Cómo me hice monja se demuestra la correlación de tiempos verbales primero en términos de anterioridad: "Mi historia, la historia de cómo me hice monja, comenzó muy temprano en mi vida...", para luego dar lugar a acontecimientos presentes, "El comienzo está marcado con un recuerdo vívido", manifestando así las relaciones de orden temporal entre los eventos. Para Pimentel, la lengua misma cuenta con la capacidad para expresar y diversificar nuestra experiencia temporal relativizada en capas y niveles de temporalidad que pueden articularse y coordinarse en términos de simultaneidad. ${ }^{9} \mathrm{Se}$ puede pues expresar anterioridad o posterioridad, no sólo en relación con el presente, sino con el pasado e incluso con el futuro, tal como ocurre en el fragmento mencionado en donde la anterioridad se hace presente al referir el comienzo de la historia y la

\footnotetext{
${ }^{7}$ Luisa Puig, "Los implícitos discursivos: un enfoque retórico", Acta poética 14, núm. 1 -2 (2013): 222.

${ }^{8}$ Luz Aurora Pimentel, Constelaciones I. Ensayos de teoría narrativa y literatura comparada (México: Bonilla Artigas Editores / Universidad Nacional Autónoma de México, 2012), 37.

${ }^{9}$ Ibidem. 


\section{enn-claves}

Revista de Filosofía, Arte, Literatura, Historia

posterioridad en el sólo recuerdo vívido que perdura en el futuro. Esta capacidad de articular niveles de temporalidad es lo que posibilita el discurso narrativo y una de las peculiaridades en esta obra de Aira.

Reconocer el orden cronológico de la narración implica preguntar ‘¿cuándo?’ en relación con los acontecimientos; si los casos en que los acontecimientos no ocurren en una secuencia temporal cronológica y ordenada estamos frente a una anacronía. Anacronía como tal es la desviación del estricto orden cronológico de la historia. Es común que Aira recurra - no sólo en Cómo me hice monja sino en diversas obras- a la anacronía como herramienta narrativa, principalmente, utilizando la analepsis como la presentación de eventos que ocurrieron con anterioridad a la historia que se está narrando en el momento, brindando así una programación temporal peculiar a lo narrado. Sin duda, no es exclusivo de Aira el uso de la analepsis, no obstante, la recurrencia por parte del autor y el logro de un orden lógico sustancial a pesar de las transgresiones de orden temporal, lo ubican como un escritor analizado por el uso fuera de lo común de la temporalidad.

Al comenzar la novela con un recuerdo, el autor permite identificar que, si bien es capaz de dar continuidad a la historia aun con los movimientos temporales, recuerdos de la infancia, momentos del presente, otros que no han ocurrido, también es capaz de establecer la diferencia entre un momento y otro.

Me caían lágrimas innumerables, y el helado se derretía francamente, los hilos rosas me corrían hasta el codo, desde donde goteaban hasta la pierna. Pero no hay situación que se eternice. Siempre pasa algo más. Lo que sucedió entonces vino de mi cuerpo, de lo profundo, sin preparación alguna, por la voluntad o la deliberación. ${ }^{10}$

En este fragmento del corpus también es posible identificar un implícito discursivo vinculado con la categoría de tiempo desde el devenir. Para Margarita Remón, las novelas del autor argentino suelen referirse a un movimiento cíclico, a través de un insistente retorno a la posición inicial. ${ }^{11}$ Es justamente este retorno a la posición inicial, retorno que usualmente aparece como presente de referencia, el que denota peculiaridad

\footnotetext{
${ }^{10}$ Aira, Cómo me hice monja, 16-17.

${ }^{11}$ Remón, "Narrativa de César Aira", 53.

En-claves del pensamiento, Año XIV, Núm 27, enero-junio 2020, 39-58
} 


\section{enn-claves}

Revista de Filosofía, Arte, Literatura, Historia

en Aira quien evita el uso del presente referencial para dar lugar a movimientos temporales y en oposición echa mano del pasado como punto de partida. Se puede afirmar que los acontecimientos señalados, relatados como recuerdos, son el tiempo principal sobre el que se construyen todas las desviaciones anacrónicas, y es precisamente éste el elemento novedoso: partir de una matriz de recuerdos y no necesariamente del presente en que se está narrando. Los recuerdos de la infancia atienden al retorno mencionado y a un movimiento que no puede darse sino gracias a la temporalidad entre escenas del pasado, del presente, así como otras que al ser de un pasado que se hace vivencia en el momento se manifiestan como presente, aun cuando no lo son. En este fragmento, el implícito discursivo puede reconocerse teniendo en cuenta el principio de cooperación ${ }^{12}$ de acuerdo al cual la contribución conversacional debe corresponder con lo que se exige, en función del objetivo del intercambio. Así, el implícito discursivo se construye a partir de dos consideraciones: la cantidad de información que se suministra y la veracidad de lo enunciado; en este caso el autor indica que lo ocurrido en el primer momento de la narración no podría eternizarse, debía terminar y dar paso a otros eventos, no obstante deja sin aclarar o hacer explícita la condición temporal de un hecho que desencadena la historia y que si bien concluye como momento, se mantiene presente en una dinámica temporal, en tanto se remite a él en recuerdos que brindan sentido a la narración. Al afirmar que siempre pasa algo más la categoría de tiempo se hace presente, aunque de manera vedada, pues la cantidad de información que se suministra no es suficiente. Por otro lado, la calidad de la contribución o su veracidad también impacta en el implícito discursivo, es decir, no sólo la cantidad de información puede ser un factor para el sobreentendido, también lo puede ser la duda respecto a la veracidad de que lo acontecido sea por voluntad del protagonista o no, poniendo en entredicho la transformación y el devenir de la narración, y, por lo tanto, el tiempo en el que se desarrolla. Para Luisa Puig pareciera que el implícito no está del todo en el decir del locutor, sino en gran medida también en quien recibe la información. ${ }^{13}$ A esto se le suma que lo implícito en cualquier momento puede desdecirse, el locutor puede llegar a desresponsabilizarse de lo dicho, pues gran parte del implícito tiene que ver con el

\footnotetext{
${ }^{12}$ Puig, "Los implícitos discursivos", 218.

${ }^{13}$ Ibid., 220. 


\section{en-claves}

proceso de decodificación. Estos rasgos son comunes en la escritura de Aira, sin ser exclusivos de Cómo me hice monja el autor los incluye en varias de sus novelas cortas en donde constantemente la estructura narrativa de los hechos se modifica en función de una configuración lógica que no necesariamente atiende a una configuración cronológica secuencial.

En Cómo me hice monja la categoría de tiempo también se hace presente a través del continuum narrativo, que muestra otra de las facetas de la categoría de tiempo.

Las primeras semanas pasaron en forma de imágenes puras. El ser humano tiende a darle sentido a la experiencia mediante la continuidad, lo que sucede se explica por lo que sucedió antes: no puede sorprender que yo persistiera en mi reciente acomodación a Ana Módena y siguiera viendo gestos, mímica, historias sin audio, ante las cuales no podía hacer nada. ${ }^{14}$

Este fragmento del corpus demuestra una vez más la incursión del concepto de tiempo, ahora desde la continuidad que permite la comprensión de la propia existencia a partir de una sucesión ordenada de momentos. Cuando el protagonista de esta pequeña novela reconoce en su propia experiencia la capacidad de explicar lo que ocurre en el presente a la luz de lo sucedido con anterioridad, permite establecer como un presupuesto la condición temporal de la narración y asegura la coherencia en función de un orden y continuo temporal. Santos, en su análisis de la ficción y las series, afirma que la escritura de Aira suele despertar en el lector un extrañamiento que viene de reconocer que muchos sucesos no pueden ocurrir en el condensado ritmo que presenta la novela, ${ }^{15}$ a pesar de ello en los fragmentos seleccionados del corpus y analizados se demuestra que también es capaz de mantener un continuum y que tal como lo reconoce Santos "el tiempo se transforma en un flujo continuo [...] con estos datos el lector puede reconocer el terreno que pisa y aceptar plácidamente el juego ficcional al que es invitado a aparecer". ${ }^{16}$ En su artículo "Hacia una nueva propuesta teórica de sistematización de los estratos del texto narrativo", Valles Calatavra identifica a la historia como la secuencia de hechos temporalmente ordenados, provocando en el lector el deseo de saber qué es lo que va a

\footnotetext{
${ }^{14}$ Aira, Cómo me hice monja, 42.

15 Lidia Santos, "Cómo la ficción consume las series: Radionovelas, telenovelas y la narrativa latinoamericana contemporánea", Global Media Journal Edición Iberoaméricana, núm. 2 (junio, 2004): 35.

${ }^{16}$ Ibidem. 


\section{en-claves}

Revista de Filosofía, Arte, Literatura, Historia

e-ISSN: 2594-1100, Año XIV, Núm 27, enero-iunio 2020, 39-58

suceder, interrogándose a sí mismo con preguntas como “¿y después que?”, “y luego?", ${ }^{17}$ es entonces cuando Aira al transformar la estructura narrativa de los hechos provoca el extrañamiento del lector, tal como refiere Santos, y logra un efecto estético mediante las técnicas narrativas de participación de la memoria, sin perder el sentido o el orden lógico del relato.

Para vislumbrar la innovación en la obra de Aira, vale la pena retomar lo postulado por Genette, quien reconoce el tiempo interno o narrativo como el que abarcan los acontecimientos que transcurren en la acción; de acuerdo a la duración de estos acontecimientos es posible encontrar en la narración distintos tipos de ritmo, un ritmo lento cuando la acción dura días o incluso horas, y un ritmo rápido cuando la acción dura años o incluso generaciones. ${ }^{18}$ En este sentido, en Cómo me hice monja el ritmo del relato se define por la narración de acontecimientos ocurridos en meses en una novela relativamente corta, dando como resultado un ritmo rápido en el que el lector debe mantener presente la temporalidad para comprender la totalidad significante de la historia.

Era mi historia, no una ajena. El drama había comenzado en el momento en que pisé la escuela, y estaba todo frente a mí, entero, intemporal, yo estaba y no estaba en él, estaba y no participaba, o participaba solo por mi negativa, pero un agujero en la representación, ipero ese agujero era yo! ${ }^{19}$

Cómo me hice monja juega con las categorías de espacio y tiempo tal como se manifiesta en este fragmento. Cuando el protagonista afirma que su drama comienza en el momento en que pisa la escuela y que estaba todo frente a él, intemporal, entero, ofrece otro de los rasgos relacionados con la temporalidad. Dicho rasgo resulta común en las obras de César Aira, la capacidad de mostrar el tiempo como un todo. En Cómo me hice monja la serie de eventos narrados a través de la memoria perfecta del protagonista suelen presentarse como recuerdos, pero a la vez como un todo atemporal, justamente ahí es donde radica el implícito para la comprensión de la importancia de la categoría de

\footnotetext{
${ }^{17}$ José Valles Calatrava, "Hacia una nueva propuesta teórica de sistematización de los estratos del texto narrativo. Fábula, trama y relato como plano funcional, actuacional y discursivo", Revista de Literatura, núm. 156 (julio-diciembre 2016): 345-367.

${ }^{18}$ Gérard Genette, Análisis estructural del relato (Buenos Aires: Tiempo Contemporáneo, 1972), 207.

${ }^{19}$ Aira, Cómo me hice monja, 42.

En-claves del pensamiento, Año XIV, Núm 27, enero-junio 2020, 39-58 


\section{en-claves}

tiempo en la novela, en la capacidad de la narración para arrastrar al lector a un mundo posible que establece como principio de realidad básico un espacio y tiempo que le son propios y que operan bajo su propia lógica.

Todo este relato que he emprendido se basa en mi memoria perfecta. La memoria me ha permitido atesorar cada momento que pasó, también los instantes eternos, los que no pasaron, que encierra en su cápsula de oro a los otros. Y los que se repitieron, que por supuesto son los más. ${ }^{20}$

El propio Aira reconoce en voz del narrador la eternidad de los instantes que pueden atesorarse a través de esta memoria perfecta, que si bien no explicita el papel fundamental que juega el tiempo si lo deja ver parcialmente. El hecho de mencionar la repetición y el atesoramiento de los recuerdos, indica desde el implícito justamente lo que ya se le atribuye al autor, una recurrencia o narración cíclica en la que el sentido aparece a partir del regreso de instantes. Pimentel explica la capacidad del mundo narrado como mundo posible, "un mundo de ficción que es real, paradoja que es preferible evitar por medio del concepto genettiano de universo diegético: un mundo de ficción que es considerado realidad por sus habitantes, con unas coordenadas espacio-temporales que designa la propia ficción", ${ }^{21}$ es decir, en el mundo ficcional creado por Aira las coordenadas espacio-temporales difieren de la realidad sin que esto obligue al relato a perder sentido. Jorge Iglesias reconoce a César Aira como un escritor con un impulso de continuo cuya escritura mantiene la intención de una huida hacia adelante, ${ }^{22}$ este deseo de que el relato continúe a toda costa, a pesar de tratarse de relatos breves, influye directamente en la noción de temporalidad que logra un orden lógico con desviaciones cronológicas.

A partir del análisis de los fragmentos seleccionados y de algunos teóricos que presentan estudios sobre las obras de Aira, la narratología y las concepciones temporales en la literatura, se alcanza la afirmación de que la temporalidad discontinua de las narraciones no sólo puede ir de un recuerdo a un momento presente, para luego exponer

\footnotetext{
${ }^{20}$ Ibid., 63.

${ }^{21}$ Pimentel, Constelaciones I, 51.

${ }^{22}$ Eduardo Iglesias, "En breve: modos de la novela corta en el cono sur" [Tesis doctoral] (Departamento de Estudios Hispánicos de la Universidad de Houston, 2012), 90. 


\section{enn-claves}

Revista de Filosofía, Arte, Literatura, Historia

algo que todavía no ha ocurrido pero que forma parte del pasado de algún personaje, sino que además modifica la manera en que estos personajes experimentan el tiempo. La multiplicidad de acontecimientos y un discurso que orienta a la ficción contribuyen a ello.

¿Qué el helado no me gustaba? Ya se lo había dicho. ¿Qué el sabor del helado era inmundo? También se lo había dicho, pero era algo que no valía la pena decir, que aún después de decirlo seguía en mí, incomunicable. Porque a él le gustaba, le parecía exquisito. Todo era imposible, para siempre. ${ }^{23}$

La experimentación del tiempo es peculiar y múltiple para los personajes. Cuando el niño César no quiere comer el helado que su padre le ha comprado, por su detestable sabor, aquel instante de insistencia y capricho, se extiende dando la impresión de ser muy largo, cuando en realidad se narran tan solo unos minutos. Para que la novela fuera posible en la exacta medida de elementos autobiográficos y ficticios, ha sido necesario utilizar tal como se ha descrito, la noción de tiempo, desde diversas perspectivas. También en otro momento de la novela se representa esta experimentación peculiar del tiempo.

Todas las cosas que habían ocurrido, habían contribuido a hacer pasar el tiempo. De pronto yo, que no advertía nada, sentía que el aire cambiaba de consistencia, que hacía menos frío, que los días eran más largos... Llegaba la primavera. Era como si el año quedara atrás, y al hacerlo se fundiera en un bloque muerto, extraño a mí. Secretaba todas las pequeñas diferencias, los movimientos, temblores, pensamientos, los expulsaba a todos al presente, donde yo palpaba una novedad un poco salvaje que embriagaba [...] Era más bien la percepción de un ciclo, pero como mi vida, podría decirse, había empezado ese otoño, poco después de nuestra llegada a Rosario, no veía el cielo en su repetición, sino en su línea recta. ${ }^{24}$

Aquí el/la protagonista César reconoce que su propia percepción del tiempo varía en relación a la percepción regular del mismo, no sólo en una posible aceleración caracterizada por la sensación de devenir, sino también por la percepción del tiempo como bloque, como un todo. La construcción discursiva de este fragmento recurre a la descripción de las propias sensaciones, "movimientos, temblores, pensamientos", para

\footnotetext{
${ }^{23}$ Aira, Cómo me hice monja, 14.

${ }^{24}$ Ibid., 89. 


\section{enn-claves}

expresar de forma implícita la experiencia de la temporalidad. Por tanto, la percepción del tiempo puede ir del devenir a una posición estática y estable. Retomando a Pimentel y la relación entre temporalidad y ficción, "Es el lector quien, en el tiempo, va operando la síntesis: literalmente va construyendo gradualmente los lugares y objetos, corrigiendo, aumentando y modificando imágenes a partir de descripciones parciales y recurrentes que dentro de su imaginación acaban haciendo un mundo". 25 La construcción de ese mundo autoficcional en donde el autor mezcla elementos de su propia vida con eventos ficticios solo puede comprenderse si se desenvuelve en un fondo temporal que el lector hace propio.

\section{Espacio y la huida en la novela corta}

Si la categoría de tiempo en las novelas de Aira no ha sido profundamente analizada, mucho menos la de espacio. En esta categoría en particular resulta fundamental la metodología utilizada, pues es a través del análisis del discurso y de la identificación de los implícitos discursivos que es posible reconocer la importancia del espacio en Cómo me hice monja. Para comenzar es importante referirse al espacio como el soporte de la acción, el marco o lugar donde suceden los acontecimientos. Los espacios pueden ser ficticios o reales, pero también de carácter real o alucinante.

El cuerpo como espacio aparece en esta obra como en ninguna otra relacionado con la identificación. En su análisis de la ficción de la novela latinoamericana Santos reconoce nociones de espacio que se anclan a una crisis de representación a partir de la memoria. ${ }^{26}$ Algunos fragmentos del corpus analizado muestran implícitos discursivos que no se diferencian de los explícitos por su estatuto, sino por su modo de presentación, para ejemplo la narrativa que no reconoce el género del narrador y en donde el espacio del cuerpo no es identidad. Los dos fragmentos presentados a continuación muestran lo mencionado.

Yo estremecida, trémula, húmeda, con el vaso de helado en una mano y la cucharita en otra, la cara roja y descompuesta en un rictus de angustia, no estaba menos inmovilizada. Lo estaba más, atada a un dolor que me superaba

\footnotetext{
${ }^{25}$ Pimentel, Constelaciones I, 52.

${ }^{26}$ Santos, "Cómo la ficción", 35. 


\section{en-claves}

con creces, dando con mi infancia, con mi pequeñez, con mi extrema vulnerabilidad, la medida del universo. ${ }^{27}$

Debo decir en mi descargo que lo improvisaba todo. Aunque tenía verdaderos eones para pensar, nunca los usaba para eso.

— ¿Cómo anda hoy Don César? Qué bien se lo ve Don César. ¿Ya quiere ponerse a jugar al fóbal Don César? A ver cómo andamos Don César. ${ }^{28}$

En ambos fragmentos es posible determinar la dualidad de referencias en cuanto al género del protagonista, ya que, si bien él mismo se reconoce en el género femenino, la gente se refiere a él en masculino. Para establecer el sentido de los implícitos discursivos, es decir, para llegar a la implicatura hay que ir más allá del significado convencional de las palabras, ${ }^{29}$ partiendo de esto y en vinculación con los dos fragmentos aquí incluidos el espacio corporal con el cual se identifica el/la protagonista se relaciona con una crisis de representación, el espacio del cuerpo, por tanto, no es identidad. En este caso en particular, el implícito parte de una doble función, la del presupuesto, que al usar el nombre César debe tratarse de un niño, pero también la del sobreentendido de que debe tratarse de una niña, pues se refiere a sí misma en femenino. De aquí se infiera que la categoría de espacio se construye a través del discurso, principalmente, a partir de lo relacionado con el cuerpo que no coincide con la identidad y que permea en el sentido del texto a partir de implícitos, esto debido a una crisis de representación.

Lo que más se acercaba a la cárcel en mi experiencia era el hospital. En ambos casos se trataba de encierros prolongados. Pero había una diferencia. Del hospital no se podía salir por una causa interna: el paciente, como yo había demostrado, estaba imposibilitado de moverse. De la cárcel en cambio no se podía salir por otro motivo. No sabía bien cuál: la fuerza era un concepto todavía confuso para mí. Me hice una idea mixta cárcel-hospital. Había un invisible que se trasladaba de uno a otro. El desvanecimiento de la enfermedad, y una transferencia al prójimo de la conciencia enferma... Era el plan de evasión perfecto. Quizás papá podría volver a casa con nosotras. En este edificio demasiado realista yo irradiaba mi magia... Si papá estaba aquí por mi culpa. ${ }^{30}$

\footnotetext{
${ }^{27}$ Aira, Cómo me hice monja, 15.

${ }^{28}$ Ibid., 33.

${ }^{29}$ Beatriz Gallardo, "El sobreentendido", Pragmalingüística, núm. 3-4 (1995): 5.

${ }^{30}$ Aira, Cómo me hice monja, 56. 


\section{en-claves}

Revista de Filosofía, Arte, Literatura, Historia

En el anterior fragmento del corpus encontramos una vez más la construcción discursiva de espacio implicada en sobreentendidos, por ejemplo, en el hecho de que el espacio del hospital y el de la cárcel finalmente son prisiones para quienes ahí dentro se encuentran. Los prisioneros están en esa condición por diversos motivos, la ausencia de salud o un delito cometido, sin embargo, en ambos casos el espacio se manifiesta como un límite, como estructura. En este texto en particular el sobreentendido radica en la comprensión de las similitudes entre la cárcel y el hospital, pues, aunque sus diferencias se explicitan, las concordancias no. Además, también es posible reconocer el implícito en el fragmento a través del presupuesto, cuando el narrador se refiere a una transferencia al prójimo de la conciencia enferma y a la evasión perfecta, abre la puerta a la presuposición de que las normas en que el espacio se maneja en la realidad pueden flexibilizarse o romperse alcanzando la ficción. Sin duda, el espacio también es fundamental para el desarrollo de la historia en Cómo me hice monja, sobre todo si se considera la noción de Rimmon-Kenan que aborda el espacio como elemento de focalización en la narrativa, es decir, como el punto de vista desde el cual el lector asigna el significado a lo narrado, a los acontecimientos. Espacio como categoría dentro de la narrativa de Cómo me hice monja se transforma constantemente y ofrece las condiciones necesarias para el desarrollo de la historia tal como ocurre.

Tres posibles aproximaciones a la categoría de espacio son el espacio como construcción, como producción o como representación a través de las palabras. En todos los casos el espacio parte del discurso narrativo que en Cómo me hice monja es pilar para el relato. Si bien, los implícitos de la categoría de espacio no son tan recurrentes como los de tiempo en la producción literaria de César Aira, también se trata de una noción fundamental para el desarrollo de su novela de vanguardia y la posibilidad de interpretación de sus obras, considerando que juega con elementos ficcionales para la creación de espacios más allá de la realidad. 


\section{enn-claves}

Revista de Filosofía, Arte, Literatura, Historia

e-ISSN: 2594-1100, Año XIV, Núm 27, enero-iunio 2020, 39-58

\section{Construcción discursiva de los conceptos de espacio y tiempo en Cómo me}

\section{hice monja}

El escritor argentino César Aira ha destacado como autor de obras consideradas vanguardistas, pues además de incluir elementos autobiográficos en sus novelas cortas ha incluido ficción, logrando relatos donde las concepciones espacio-temporales rompen los esquemas tradicionales. Para Donoso, en Aira la vanguardia funciona como una especie de matriz potenciadora de invención, dicha matriz logra que hechos totalmente inconexos encuentren su punto de relación en el relato, llegando así a conformar una trama coherente y continua. ${ }^{31}$ Parecería que justamente de ahí nace el auge de la escritura airana como objeto de estudio, las narraciones del autor, sumamente singulares, originan su peculiaridad en gran medida en una construcción discursiva en la línea de la ficción realista que permite reconocer colaboraciones de las categorías de espacio y tiempo, conjunciones de acontecimientos que oscilan entre el pasado y el presente, así como espacios que pueden ser dimensionados como cuerpo, identidad, otredad, etc. En Constelaciones I. Ensayos de teoría narrativa y literatura comparada, Luz Aurora Pimentel postula que el espacio-tiempo define al mundo narrado, en este se desarrolla la acción y ocurren en él los acontecimientos que se van tramando en una configuración que acusa una orientación temática intencional; ${ }^{32}$ en Cómo me hice monja, César Aira logra la orientación temática intencional a través de una serie de desviaciones temporales y configuraciones espaciales fuera de lugares e identidades comunes, por ejemplo, el/la protagonista identificado/a con un cuerpo-espacio bigenérico y su recurrencia a memorias que permitan establecer la secuencia lógica del relato. Pimentel también afirma que la realidad narrativa de cualquier relato está centrada en el tiempo, ${ }^{33}$ justamente por esta importancia de la categoría de tiempo en cualquier relato es que Aira se presenta como innovador al arriesgar la secuencia de eventos con saltos temporales y una matriz de recuerdos que permite mantener el sentido, "Como bien lo muestra nuestra experiencia de

\footnotetext{
${ }^{31}$ María de los Ángeles Donoso, "La vanguardia y sus retornos: confabulaciones del presente en cuatro escritores latinoamericanos" [Tesis doctoral] (Escuela de Artes y Ciencias de la Universidad de Washington, 2010), 12.

${ }^{32}$ Pimentel, Constelaciones I, 267.

${ }^{33}$ Ibidem. 


\section{enn-claves}

Revista de Filosofía, Arte, Literatura, Historia

lectura, un mundo de ficción se consume y se consuma en el tiempo", ${ }^{34}$ Aira lo comprende cuando crea en Cómo me hice monja un mundo de ficción consumado en una dinámica narrativa basada en un tiempo que mantiene la sucesión de eventos sin que sean necesariamente consecutivos.

La escritura de Aira expresada como pura potencia se manifiesta en una construcción discursiva que juega con los términos y que constantemente mantiene una delicada insinuación a la ruptura con la delimitación espacial y temporal. La gran mayoría de las novelas del escritor argentino ofrecen una perspectiva temporal de los relatos que se ubican en un pasado anterior, que no ha tenido nunca efectivamente lugar. ${ }^{35}$ Es decir, los acontecimientos narrados en el pasado aparecen en la memoria perfecta de los protagonistas sin que necesariamente se ofrezcan elementos para confirmar que realmente hayan tenido lugar. En Cómo me hice monja esto se presenta con ambas categorías: espacio y tiempo.

Yo estaba sola en casa. Papá y mamá habían tenido que ir a un velorio y me habían dejado encerrada... en aquella vieja casita de Pringles en la que ya no vivíamos... sola con mis cuatro historietas dando vueltas en la cabeza...mi corona de espinas...Las dos puertas estaban con llave, bajadas las persianas de madera de las ventanas... una caja fuerte para el tesoro de vida que tenían mis papás: yo. El realismo era minucioso, hermético... Pero cuando digo que estaba sola, que la casa estaba cerrada, que era de noche...no son circunstancias, no son elementos sueltos con los que armar una serie... La serie era exterior (la inundación, la nutria, los bombones, el secreto) y agotaba todas las reservas delirantes de mi fiebre... Aquí ya no quedaba sino el bloque de realidad, inmanejable, el verosímil rabioso... ${ }^{36}$

La memoria perfecta de la protagonista se presenta implícita discursivamente en los recuerdos que puede narrar de manera precisa y que, no obstante, desdibujan la realidad incluyendo elementos que van más allá de las normas de lo que se considera realista. El bloque de realidad al cual se remonta este fragmento hace coincidir dimensiones espacio-temporales que posibilitan la narración de la historia tal como ocurre, estableciendo al espacio a partir de sobreentendido de que es aquel en donde se

\footnotetext{
${ }^{34}$ Ibidem.

${ }^{35}$ Donoso, "La vanguardia", 119.

${ }^{36}$ Aira, Cómo me hice monja, 27.

En-claves del pensamiento, Año XIV, Núm 27, enero-junio 2020, 39-58
} 


\section{en-claves}

atesora o guarda su propio cuerpo, ya sea la casa o la habitación en que se encuentra, así como al tiempo en una serie de momentos en devenir que se experimentan como extraños, y no necesariamente por la fiebre. La temporalidad se marca por el recuerdo, una narración en retrospectiva, que además superpone el pasado que revive con la memoria a un presente que resulta también pasado: "Yo estaba sola en casa. [...] en aquella vieja casita de Pringles en la que ya no vivíamos...", el relato ocurre en un pasado que incluso en el futuro es presente ya ocurrido. A la par de la construcción del tiempo aparece el espacio, "Hemos venido insistiendo que la representación del espacio del relato se cumple en buena medida por la descripción de los lugares y objetos que lo pueblan conformando así el escenario indispensable para toda la acción narrada", ${ }^{37}$ que en este caso retoma las particularidades de la casa.

La lectura en conjunto de las novelas de Aira facilita la identificación del continuum que caracteriza la categoría de tiempo en su producción. Esta noción del continuo se percibe en gran medida en que la serie de acontecimientos extraños o que resulta difíciles de relacionar entre sí ocurren invitar al lector a detenerse a buscar un sentido, "Las novelas de Aira actualizan el continuo a partir de una serie de pliegues y repliegues que van de la generación a la degeneración". ${ }^{38}$ Esta continuidad no sólo se presenta en el dinamismo sino también en la constante vuelta o ese retorno que suele aparecer en las novelas del autor, una suerte de clave que hace retornar a las historias a lugares impredecibles, pero que también hace volver a la vanguardia a sus orígenes.

El tiempo y el espacio finalmente se conjugan en la identidad propia, en el/la protagonista que se concibe en esa doble dimensión.

Me aferré al tiempo; y consiguientemente a la pedagogía, la única actividad humana que pone al tiempo de nuestra parte.

De ahí que haya caído en algo, por una vez, característico de una niña de mi edad, como es la identificación con la maestra. Todas las niñas pasan por esa etapa, y por esa actividad casi febril de darle clase a sus muñecas o a los niños imaginarios que las habitan. Qué ridículo, que quien nada sabe se ponga a enseñar con tanto ahínco. Pero que ridículo sublime. Qué catecismos de

\footnotetext{
${ }^{37}$ Pimentel, Constelaciones I, 268.

${ }^{38}$ Donoso, "La vanguardia", 122. 


\section{en-claves}

Revista de Filosofía, Arte, Literatura, Historia

dogma didáctico salvaje están esperando ahí al observador sagaz. Que moral de la acción. ${ }^{39}$

El niño César, protagonista de la historia deja entrever la importancia del tiempo para su propia existencia y el relato de su historia en este fragmento en que la construcción discursiva coloca al tiempo como elemento fundamental para reconocer a sí misma. El aferrarse al tiempo, que explícitamente expresa la temporalidad de la escena, también deja ver de forma implícita la necesidad de una categoría que le define, César no es sino en el tiempo, uno que continuamente se le escapa. En cuanto al espacio una vez más se remite a la identidad del cuerpo, como lo suelen hacer las niñas de su edad, por fin César busca identificarse en alguien más, en este caso su maestra que si bien no explicita o aclara que se reconozca en el cuerpo de esta mujer adulta, si se despliega como lo hace la maestra en ademanes y actitudes pedagógicas que únicamente pueden tener lugar en un espacio predeterminado.

En general, la construcción discursiva de las categorías de espacio y tiempo en la obra, a través de implícitos, se desarrolla utilizando justamente las dos posibilidades que ofrecen los sobreentendidos y los presupuestos: ofrecer información de manera limitada, es decir una cantidad que únicamente permita implicar el sentido, pero no explicitarlo, y la calidad de dicha información, si la veracidad de lo afirmado puede ponerse en tela de juicio entonces abre la posibilidad a un implícito. ${ }^{40}$ En cualquiera de los casos, y partiendo de los fragmentos analizados, no se trata únicamente aquello, ofrecido por el autor o locutor, sino también de un fingimiento que lleva al lector a suponer que en la escritura se intentado que quien lee sobreentienda algo. Así, la relación entre lo implícito y lo explícito se sitúa en el decir algo y el hacer que alguien piense algo, pues al no participar de lo obvio y buscar la inferencia en el lector, ese hacer que se piense algo desempeña un papel preponderante.

En este sentido, el gran acierto de Aira consiste en la posibilidad de cancelar los implícitos que ha incluido en sus obras a través de la adición de nuevas informaciones, que limiten al significado convencional de las palabras a diferencia de la implicatura, que obliga al lector a aventurase más allá del significado convencional de las palabras. La

\footnotetext{
${ }^{39}$ Aira, Cómo me hice monja, 72.

${ }^{40}$ Puig, "Los implícitos discursivos", 219.

En-claves del pensamiento, Año XIV, Núm 27, enero-junio 2020, 39-58
} 


\section{enn-claves}

deducción que debe realizarse a partir del principio de cooperación en la lectura de las obras de Aira, es justamente una pieza importante del goce al acercarse a ellas y quizá en gran medida uno de los elementos que lo colocan en el sitio que hoy se encuentra, como un autor de vanguardia e innovador que constantemente renueva su propia escritura.

Todo acto de narración instaura un mundo posible con unas coordenadas espacio-temporales y una red de relaciones sociales e intersubjetivas que le son propias y que definen el nivel de realidad del relato, independientemente de que los espacios, tiempos y personas de este mundo tengan o no un referente en el mundo del extra-texto, es decir en el mundo real, el nuestro. ${ }^{41}$

Aira instaura el mundo posible de Cómo me hice monja a partir de la innovación en las categorías de espacio y tiempo; su importancia no radica en establecer únicamente la manera en que las dimensiones posibiliten el acontecer de los hechos en las narraciones y su continuidad, sino además en ofrecer elementos espacio-temporales que desafían las nociones regulares de ambas categorías. La construcción discursiva de Aira y su narración eluden el tiempo y a la vez lo parodian, jugando con las condiciones de continuidad de la narración, lo que puede llevar al lector a la extrañeza sin perder el hilo narrativo, y, por tanto, a enfrentarse a una novela que presenta lo posible fuera de lo real. En cuanto al espacio que es condición para establecer el acontecer narrativo, su construcción discursiva plagada de implícitos también nos muestra una categoría flexible que llega a valerse de la ficción para desplegar la potencia de la novela. En particular Cómo me hice monja y, en general, la producción literaria de Aira nos muestran una escritura experimental que se atiene a un procedimiento vanguardista, quizá sin siquiera perseguirlo, alejándose de la figura de escritor como pieza de museo, tal como el propio autor lo afirma, resultado de los críticos, y acercándose cada vez más a un escritor que experimenta con los límites de la realidad, que se atreve a tratar a la ficción como lo más cotidiano y a sacar a la literatura de su estancamiento.

\footnotetext{
${ }^{41}$ Pimentel, Constelaciones I, 267. 


\section{en-claves}

Revista de Filosofía, Arte, Literatura, Historia

\section{Bibliografía}

Aira, César. Cómo me hice monja. México: ERA, 2017.

Bal, Mieke. Teoría de la narrativa. Una introducción a la narratología. Madrid: Cátedra, 1990.

Donoso, María de los Ángeles. "La vanguardia y sus retornos: confabulaciones del presente en cuatro escritores latinoamericanos" [Tesis doctoral]. Escuela de Artes y Ciencias, Universidad de Washington, Seattle, Estados Unidos, 2010.

Gallardo, Beatriz. "El sobreentendido". Pragmalingüística, núm. 3-4 (2016): 351-381.

Genette, Gérard. Análisis estructural del relato. Buenos Aires: Tiempo contemporáneo, 1972.

Haidar, Julieta. Debate CEU-Rectoría. Torbellino pasional de los argumentos. México: Universidad Nacional Autónoma de México, 2006.

Iglesias, Jorge E. En breve: modos de la novela corta en el cono sur [Tesis doctoral]. Facultad de Estudios Hispánicos, Universidad de Houston, Estados Unidos, 2012.

Puig, Luisa. "Los implícitos discursivos: un enfoque retórico", Acta Poética, núms. 14-15 (1993): 217-234.

Pimentel, Luz Aurora. Constelaciones I. Ensayos de teoría narrativa y literatura comparada. México: Bonilla Artigas Editores / Universidad Nacional Autónoma de México, 2012.

Remón, Margarita. "La narrativa de César Aira, una sorpresa continua e ininterrumpida". Revista Hispánica de Flandes y Holanda, núm. 24 (2003): 53-64.

Ricoeur, Paul. Tiempo y narración I. Trad. Agustín Neira. México: Siglo XXI, 2007.

Rimmon-Kenan, Shlomith. Narrative Fiction: Contemporary Poetics. Nueva York: Routledge, 2002.

Santos, Lidia. "Cómo la ficción consume las series: Radionovelas, telenovelas y la narrativa latinoamericana contemporánea". Global Media Journal Edición Iberoamericana I, núm. 32 (2004): 32-40.

Valles Calatavra, José. "Hacia una nueva propuesta teórica de sistematización de los estratos del texto narrativo. Fábula, trama y relato como planos funcional, actuacional y discursivo". Revista de Literatura, núm. 156 (julio-diciembre, 2016): 345-367. 